\title{
OPTIMISATION OF DOPED MICROCRYSTALLINE SILICON FILMS DEPOSITED AT VERY LOW TEMPERATURES BY HOT-WIRE CVD
}

\author{
C. Voz ${ }^{*}$, D. Peiró, J. Bertomeu, D. Soler, M. Fonrodona and J. Andreu \\ Departament de Física Aplicada i Òptica, Universitat de Barcelona \\ Av. Diagonal 647, E08028-Barcelona, Spain.
}

\begin{abstract}
In this paper we present new results on doped $\mu \mathrm{c}-\mathrm{Si}: \mathrm{H}$ thin films deposited by Hot-Wire Chemical Vapour Deposition (HWCVD) in the very low temperature range $\left(125-275^{\circ} \mathrm{C}\right)$. The doped layers were obtained by the addition of diborane or phosphine in the gas phase during deposition. The incorporation of boron and phosphorus in the films and their influence on the crystalline fraction are studied by Secondary Ion Mass Spectrometry and Raman Spectroscopy respectively. Good electrical transport properties were obtained in this deposition regime, with best dark conductivities of $2.6 \mathrm{~S} / \mathrm{cm}$ and $9.8 \mathrm{~S} / \mathrm{cm}$ for the $\mathrm{p}$ - and $\mathrm{n}$-doped films respectively. The effect of the hydrogen dilution and the layer thickness on the electrical properties are also studied. Some technological conclusions referred to cross contamination could be deduced from the nominally undoped samples obtained in the same chamber after p- and n-type heavily doped layers.
\end{abstract}

Keywords: Microcrystalline silicon; Hot-Wire CVD; Doping

\section{Introduction}

In the long-term, thin film silicon technology should replace bulk crystalline silicon devices for most applications which demand cheap and large area electronics[1]. Unfortunately, the most developed thin film silicon technology, based on amorphous silicon, suffers from inherent instability and moderate electrical properties. Attempts have been made to develop thin film crystalline silicon technologies, which fulfil the low cost, large area and stability requirements[2]. The approach of polycrystalline silicon with a large grain size either requires expensive substrates compatible with high temperature processes[3] or is very time consuming in recrystallization techniques[4]. Recently, much advances have been reported on the deposition of high quality intrinsic[5] and doped[6] $\mu \mathrm{c}-\mathrm{Si}: \mathrm{H}$ by the HWCVD technique. Furthermore, the possibility to fabricate thin film devices such as solar cells[7] or field effect transistors[8] by this technique has also been demonstrated. Since doped layers are needed for these devices, the understanding of the

\footnotetext{
* Corresponding author

Tel.: 34-93-4021134, Fax.: 34-93-4021138, E-mail: cvoz@fao.ub.es
} 
doping mechanisms in the material is a key subject. In this work, we report on the compositional, structural and electrical properties of both n- and p-doped layers deposited by HWCVD in this regime. The solid phase incorporation of boron and phosphorous into silicon are compared and their doping efficiencies are discussed. Some technological aspects referred to the application of the HWCVD technique to the fabrication of device structures will be also addressed in this work.

\section{Experimental}

All the layers were deposited in a new HWCVD multichamber set up with load lock designed for obtaining thin film $\mu \mathrm{c}-\mathrm{Si}: \mathrm{H}$ devices. The pumping system, which allows a base pressure lower than $10^{-8}$ mbar, consists of a turbomolecular pump, a roots blower pump and a rotary vane pump. The gas inlet, the substrate holder, the shutter, the heater with its thermocouple and the tungsten filament $(\varnothing=0.5 \mathrm{~mm})$ are arranged as shown in Fig.1. The distance between the filament and the substrate was $6 \mathrm{~cm}$. The filament was heated by the Joule effect and catalytic cracking reactions at its surface decomposed the gas mixture during the deposition. Silicon wafer(111) and Corning 7059 glass were used as substrates. Two series of $\mathrm{p}$ - and n-doped layers were obtained by adding increasing amounts of diborane and phosphine to the silane-hydrogen gas mixture. A fresh wire was used to start both doping series from the lower towards higher doping concentrations. In order to study the effect of substrate temperature $\left(T_{s}\right)$, a third series was obtained by varying $T_{s}$ for the doping level that allowed the highest conductivity in the p-doped series. The technological values of $\mathrm{T}_{\mathrm{s}}$ used in this work are those measured with the thermocouple touching the heater. A previous calibration at typical deposition conditions with an additional thermocouple attached to the glass substrate evidenced only slight differences between both measurements. The effect of the hydrogen dilution was also investigated by obtaining samples with a different silane to hydrogen ratio. Since for devices very thin layers are usually required, we studied the effect of the thickness in the structural and functional properties of the samples by studying $\mathrm{p}$ - and $\mathrm{n}$-doped layers only $0.1 \mu \mathrm{m}$ thick. The studied samples and its main technological parameters are shown in Table I. In addition, several nominally undoped layers not included in the table were also deposited in order to study the cross contamination.

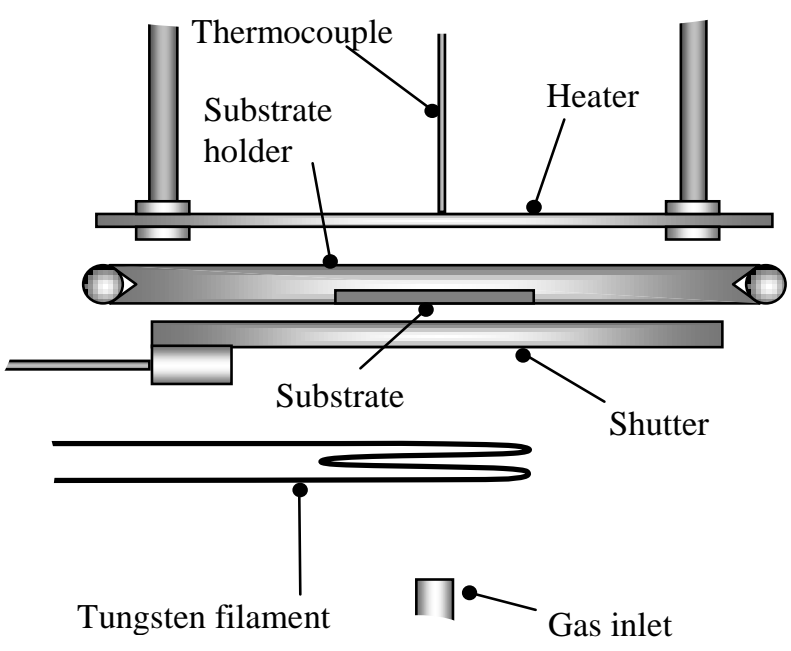

Fig. 1. Arrangement of the different elements inside the HWCVD chamber. 
The microstructure of the samples was studied by Raman Spectroscopy, X-ray diffraction (XRD) and Photothermal Deflection Spectrometry (PDS). The Raman spectra were obtained using a 514 $\mathrm{nm}$ laser radiation and an energy density of only $10 \mathrm{~W} / \mathrm{cm}^{2}$ to discard thermal effects. The XRD measurements were carried out in a powder diffractometer with $\mathrm{CuK}_{\alpha}$ radiation. The solid phase incorporation of dopants was deduced from Secondary Ion Mass Spectroscopy (SIMS) comparing our samples with patterns (ion implanted wafers) where the solid phase boron/silicon and phosphorous/silicon ratios were known. Coplanar electrical measurements were carried out by evaporating aluminum contacts on the samples obtained onto glass. Dark conductivity vs. temperature was measured in order to determine the activation energy $\left(\mathrm{E}_{\mathrm{a}}\right)$ of the samples.

Table I.

Technological parameters and room temperature dark conductivity $\left(\sigma_{\mathrm{rt}}\right)$ for the studied samples. Dilution is calculated as the ratio of the hydrogen to the silane plus hydrogen flows. $\mathrm{B} / \mathrm{Si}$ and $\mathrm{P} / \mathrm{Si}$ refer here to atomic ratios in gas phase. All the samples were obtained at a process pressure of $7 \times 10^{-3} \mathrm{mbar}$.

\begin{tabular}{c|ccccccc}
\hline Sample & $\begin{array}{c}\text { Dilution } \\
(\%)\end{array}$ & $\begin{array}{c}\mathrm{T}_{\mathrm{s}} \\
\left({ }^{\circ} \mathrm{C}\right)\end{array}$ & \multicolumn{2}{c}{$\begin{array}{c}\mathrm{B} / \mathrm{Si} \\
\text { (gas phase) }\end{array}$} & $\begin{array}{c}\text { P/Si } \\
(\mu \mathrm{m})\end{array}$ & $\begin{array}{c}\sigma_{\mathrm{rt}} \\
(\Omega \mathrm{cm})\end{array}$ & Comments \\
\hline $0427 \mathrm{I}$ & 90 & 225 & - & - & 0.5 & $1.610^{-6}$ & Intrinsic \\
\hline $0427 \mathrm{P}$ & 90 & 225 & $410^{-5}$ & - & 0.66 & $7.510^{-8}$ & P doping \\
$0609 \mathrm{P}$ & 90 & 225 & $1.610^{-4}$ & - & 0.67 & $1.210^{-7}$ & Series \\
$0428 \mathrm{P}$ & 90 & 225 & $410^{-4}$ & - & 0.68 & $310^{-6}$ & \\
$0610 \mathrm{P}$ & 90 & 225 & $1.610^{-3}$ & - & 0.8 & - & \\
$0429 \mathrm{P}$ & 90 & 225 & $410^{-3}$ & - & 0.72 & $3.410^{-3}$ & \\
$0610 \mathrm{BP}$ & 90 & 225 & $1.610^{-2}$ & - & 0.83 & $6.310^{-2}$ & \\
$0429 \mathrm{BP}$ & 90 & 225 & $410^{-2}$ & - & 0.67 & $2.710^{-4}$ & \\
\hline $0505 \mathrm{~N}$ & 90 & 225 & - & $210^{-4}$ & 0.67 & $2.810^{-6}$ & N doping \\
$0506 \mathrm{~N}$ & 90 & 225 & - & $210^{-3}$ & 0.66 & $1.610^{-2}$ & Series \\
$0506 \mathrm{BN}$ & 90 & 225 & - & $210^{-2}$ & 0.62 & 8.4 & \\
$0507 \mathrm{~N}$ & 90 & 225 & - & $210^{-2}$ & 0.63 & 9.8 & \\
\hline $0611 \mathrm{P}$ & 90 & 275 & $1.610^{-2}$ & - & 0.75 & $610^{-4}$ & $\mathrm{~T}_{\mathrm{s}}$ series \\
$0610 \mathrm{BP}$ & 90 & 225 & $1.610^{-2}$ & - & 0.83 & $6.310^{-2}$ & \\
$0611 \mathrm{BP}$ & 90 & 175 & $1.610^{-2}$ & - & 0.78 & 0.7 & \\
$0715 \mathrm{P}$ & 90 & 125 & $1.610^{-2}$ & - & 0.84 & 0.9 & \\
\hline $0304 \mathrm{P}$ & 95 & 125 & $3.810^{-3}$ & - & 0.34 & 0.06 & Higher \\
$0304 \mathrm{~N}$ & 95 & 225 & - & $3.710^{-3}$ & 0.3 & 0.11 & Dilution \\
$0223 \mathrm{~N}$ & 95 & 300 & - & $10^{-2}$ & 1.2 & 2.3 & \\
$1123 \mathrm{P}$ & 95 & 125 & $1.210^{-2}$ & - & 0.14 & 2.6 & Very thin \\
$1124 \mathrm{~N}$ & 95 & 175 & - & $4.510^{-3}$ & 0.1 & 1.1 & Layers \\
\hline
\end{tabular}

\section{Results and discussion}

\subsection{Doping series}

The mass numbers profiled by SIMS were 30 (silicon), 31 (phosphorus), 11 (boron) and 1 (hydrogen). These profiles were homogeneous except for the case of boron where a sudden increase at the film-substrate interface was observed. This result suggests an enrichment of boron atoms at the first stages of growth. Fig. 2 shows the solid phase incorporation of dopants $\left(\mathrm{N}_{\mathrm{D}}\right)$ averaged from SIMS depth profiles as a function of the dopant to silicon ratio in the gas phase for both doping series. The solid line indicates the dopant concentration for an ideal 100\% gas to solid phase incorporation. Boron solid phase densities were over this ideal efficiency for almost all the p-layers. 
Moreover, when the diborane flow was calibrated without heating, the incorporation was reduced but it still remained over this line. This result is explained by the well-known thermal dissociation of diborane[9]. We must consider that the dissociation efficiency of the hot wire is quite low at the process pressure at which the samples were obtained. Whereas the silane-hydrogen mixture was only partially dissociated by the hot wire, diborane was additionally dissociated at the hot surfaces inside the reactor. This effect enhanced the boron concentration into the films. On the other hand, phosphorus incorporation was far from the ideal efficiency, as would be usually expected. Only in the case of the sample deposited with the lowest gas phase ratio, the incorporation efficiency approached $100 \%$. However this result was not very reliable since $\mathrm{SiH}_{\mathrm{x}}$ ionised groups interfere with the phosphorus mass number.

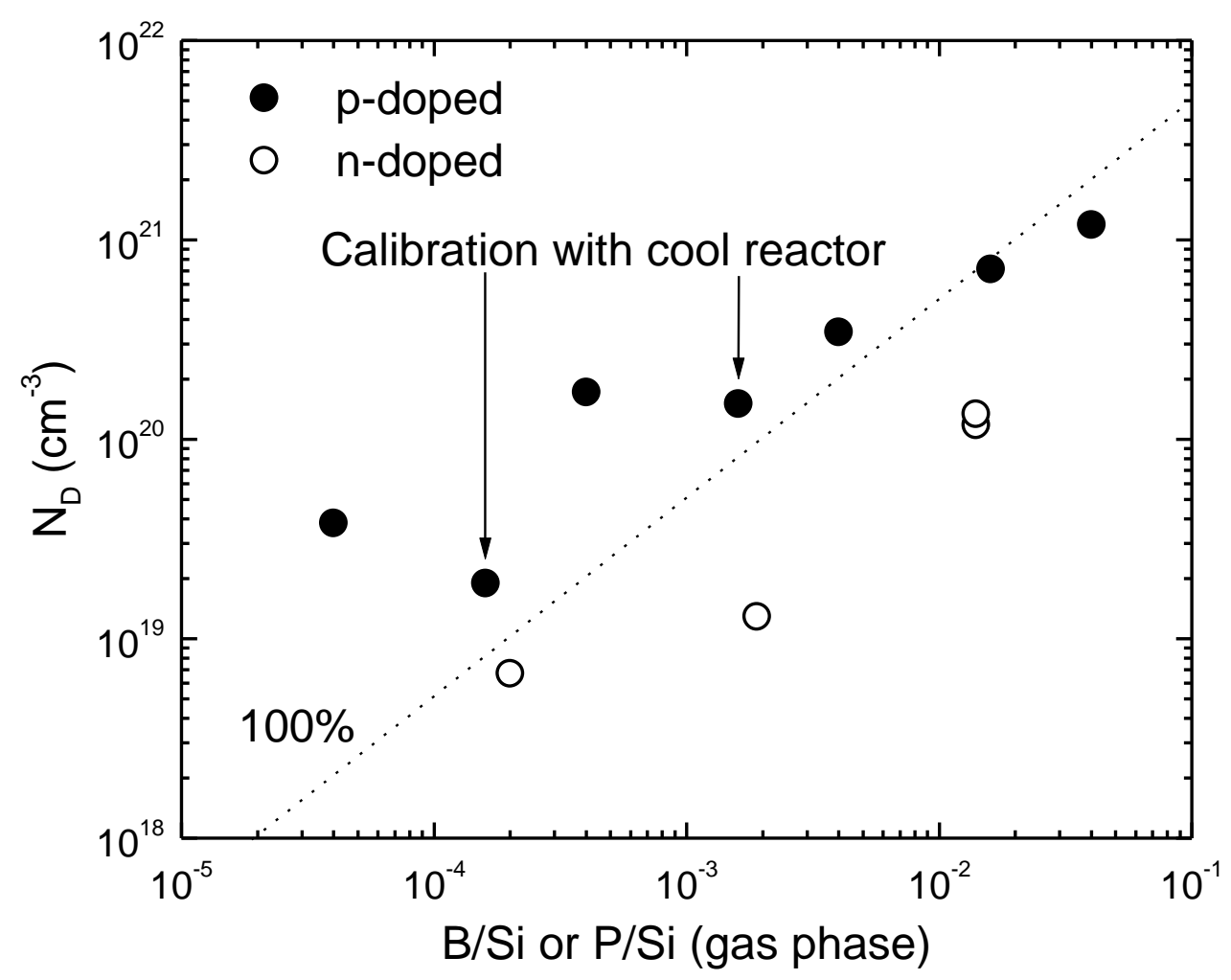

Figure 2. Solid phase incorporation of dopants deduced from SIMS as a function of the gas phase doping ratio. The dashed line corresponds to an ideal incorporation of $100 \%$.

Changes in crystallinity due to the incorporation of boron atoms were observed in the p-type doping series. In the Raman spectra the amorphous phase appears as a broad band around $480 \mathrm{~cm}^{-1}$ whereas the TO-phonon mode of the crystalline fraction arises as a sharp peak centered at $520 \mathrm{~cm}^{-1}$ [10]. The crystalline fraction $\left(\mathrm{X}_{\mathrm{c}}\right)$ was estimated from the ratio of the corresponding integral intensities for each sample. A clear decrease in crystallinity was observed for the highest B/Si ratios as shown in Fig.3. XRD and PDS measurements, not shown in this work, confirmed the same result. The same characterisation did not indicate any decrease in crystallinity, which remained around $95 \%$, in the case of n-type doping as the P/Si ratio was increased. 


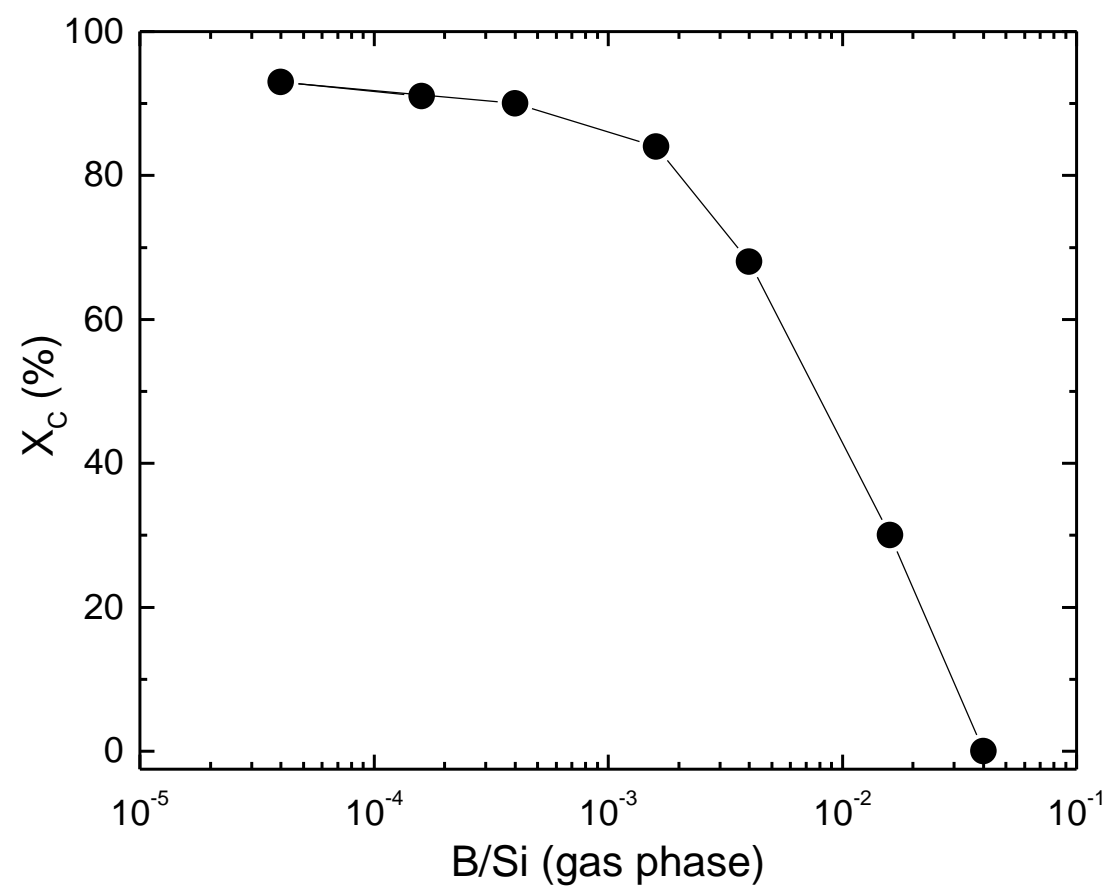

Figure 3. Raman crystalline fraction $\left(\mathrm{X}_{\mathrm{C}}\right)$ of the samples of the p-type series as a function of the gas phase doping ratio.

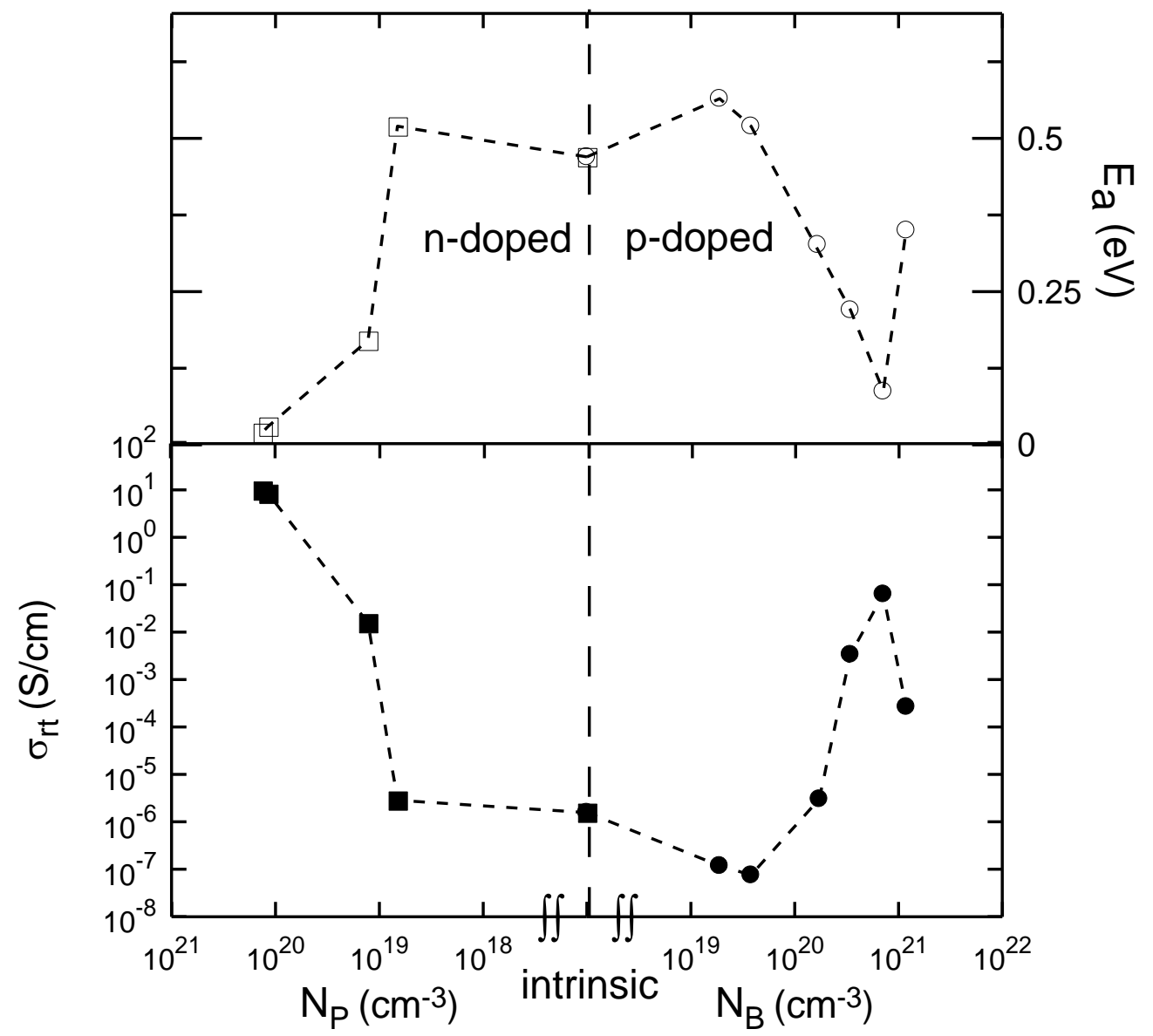

Figure 4. Dark conductivity $\left(\sigma_{\mathrm{rt}}\right)$ and the corresponding activation energies $\left(\mathrm{E}_{\mathrm{a}}\right)$ as a function of the solid phase concentration for both p-type (circles) and n-type series (squares). 
Fig. 4 shows the main electrical properties $\left(\sigma_{\mathrm{rt}}\right.$ and $\left.\mathrm{E}_{\mathrm{a}}\right)$ as a function of the solid phase dopant concentration $\left(\mathrm{N}_{\mathrm{D}}\right)$ for both $\mathrm{p}$ - and n-type series. An increase in $\mathrm{E}_{\mathrm{a}}$ and a decrease in $\sigma_{\mathrm{rt}}$ were observed in the low p-type doping level. This behaviour indicates a compensation of the unwanted n-type character of as grown undoped $\mu \mathrm{c}-\mathrm{Si}: \mathrm{H}$, usually associated to oxygen contamination. Similar results have been obtained by the group at IPE-Stuttgart[6] for similar boron concentrations $\left(\mathrm{N}_{\mathrm{D}} \sim 10^{19} \mathrm{~cm}^{-3}\right)$ with a high vacuum HWCVD set up. By contrast, in the case of $\mu \mathrm{c}-\mathrm{Si}: \mathrm{H}$ obtained by Very High Frequency CVD, the compensation was achieved at much lower concentrations $\left(\mathrm{N}_{\mathrm{D}^{\sim}} 10^{16} \mathrm{~cm}^{-3}\right)$ [11]. The incorporation of this compensated material as the active layer in $\mathrm{p}-\mathrm{i}-\mathrm{n}$ solar cells allows for an enhanced collection of photogenerated carriers[12]. The degradation of the electrical properties (decrease of $\sigma_{\mathrm{rt}}$ and increase of $\mathrm{E}_{\mathrm{a}}$ ) of the most $\mathrm{p}$-doped layer was due to its amorphisation. On the other hand, the n-type doping series showed a steady increase in $\sigma_{\mathrm{rt}}$ whereas $\mathrm{E}_{\mathrm{a}}$ decreased with the doping level.

\subsection{Effect of the substrate temperature}

A series of p-type samples was obtained in order to investigate the effect of the substrate temperature. P-type doping was chosen for this study because of the amorphisation at high doping levels evidenced in 3.1. The gas phase $\mathrm{B} / \mathrm{Si}$ ratio selected was $1.6 \times 10^{-2}$ because it gave the highest $\sigma_{\mathrm{rt}}$ in the doping series. In Fig.5 we observe a linear decrease of crystallinity when the substrate temperature was increased. The sample $0611 \mathrm{P}$ obtained at $275^{\circ} \mathrm{C}$ was essentially amorphous. Better electrical properties were obtained for the most crystalline samples, those obtained at the lowest

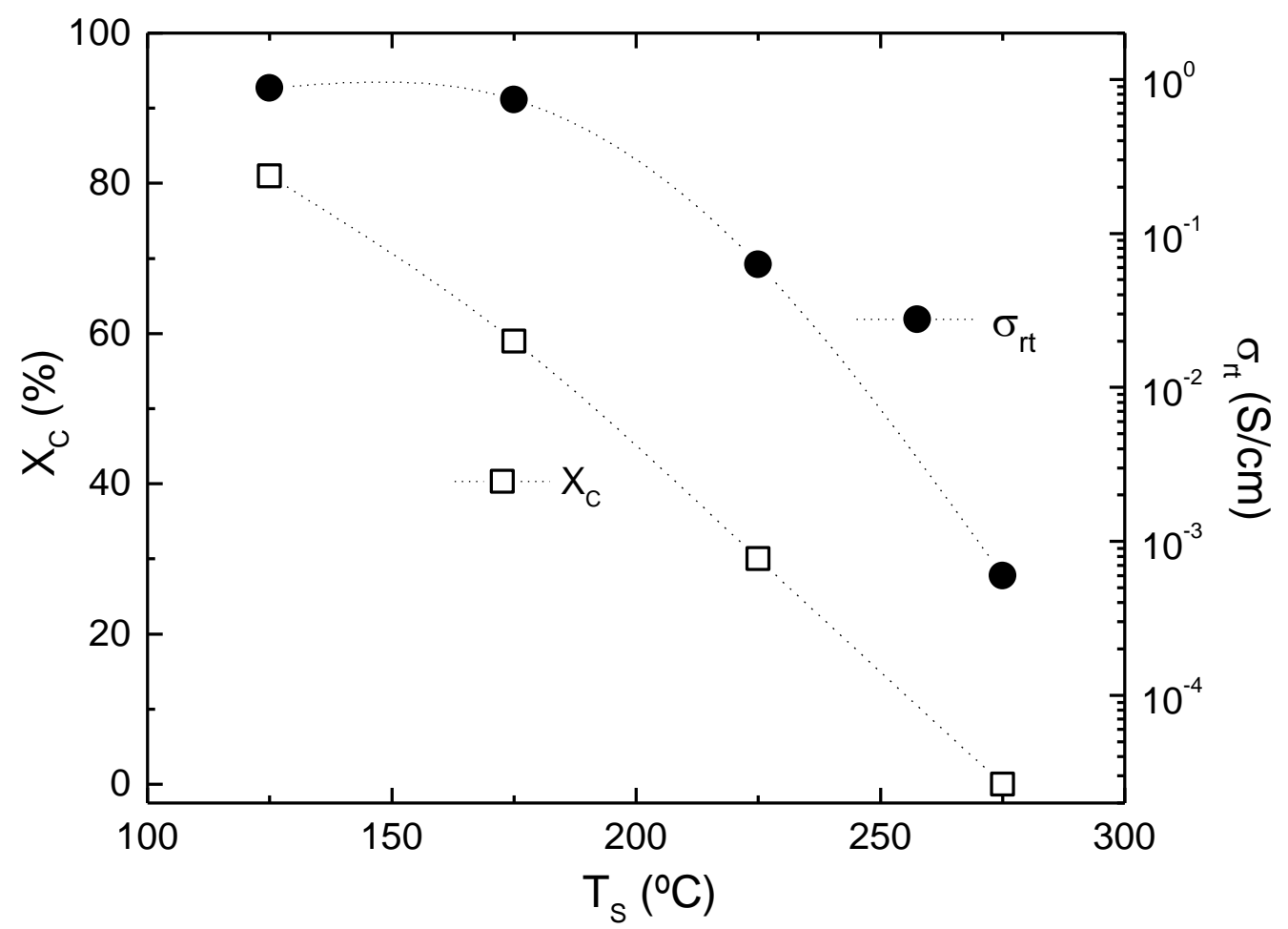

Figure 5. Raman crystalline fraction $\left(\mathrm{X}_{\mathrm{C}}\right)$ and dark conductivity $\left(\sigma_{\mathrm{rt}}\right)$ as a function of the substrate temperature $\left(\mathrm{T}_{\mathrm{s}}\right)$ for a $\mathrm{p}$-type gas phase doping ratio of $1.6 \times 10^{-2}$. 
substrate temperatures. The sample $0715 \mathrm{P}$ obtained at $125^{\circ} \mathrm{C}$ presented a $\sigma_{\mathrm{rt}}$ of $0.9 \mathrm{~S} / \mathrm{cm}$ and an $\mathrm{E}_{\mathrm{a}}$ of only $0.052 \mathrm{eV}$ with an $88 \%$ of crystalline fraction. The increase in crystallinity for decreasing substrate temperatures could seem surprising since higher crystallinity is usually expected when increasing the substrate temperature. However, this effect could be explained by structural changes when less hydrogen is incorporated due to a higher substrate temperature. Furthermore, the thermal dissociation of diborane pointed out in 3.1 could produce a too high boron incorporation into the films when the walls of the reactor and the substrate holder are at higher temperatures.

\subsection{Effect of the hydrogen dilution}

$\mathrm{P}$ - and n-type samples were obtained at a higher hydrogen dilution in order to determine its effect on the structural and electrical properties of the samples. The crystallinity and electrical properties of n-type samples did not change significatively when the hydrogen dilution was increased from 90 to $95 \%$. On the other hand, for p-type doping both the crystalline fraction and the electrical properties were improved when the hydrogen dilution was increased. For example, samples 1123P and $0715 \mathrm{P}$ were obtained at similar doping levels $\left(10^{-2} \mathrm{~B} / \mathrm{Si}\right)$, the same substrate temperature (125 ${ }^{\circ} \mathrm{C}$ ) but different hydrogen dilutions (95\% and $90 \%$ respectively). A higher crystalline fraction was

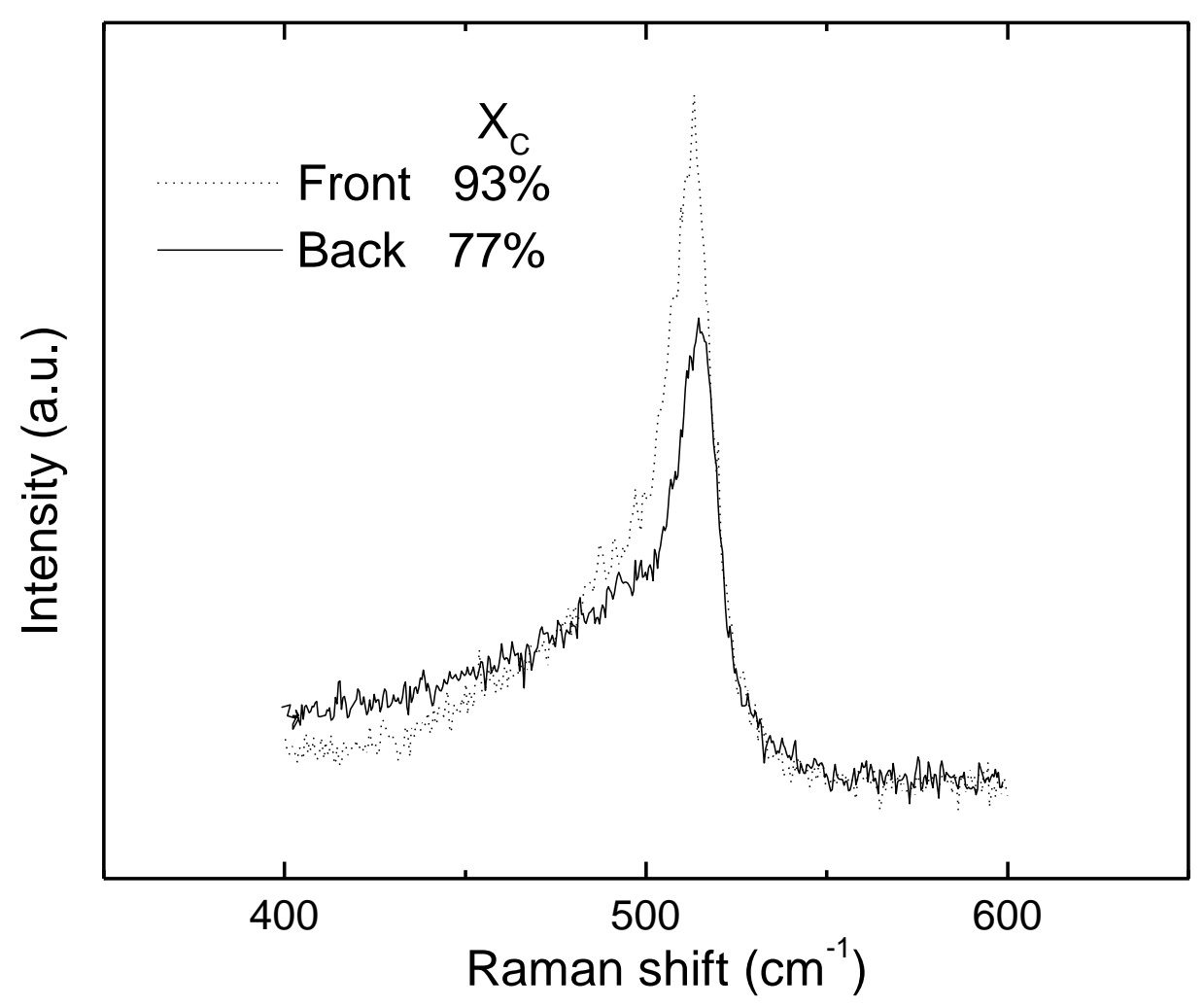

Figure 6. Raman spectra of the thin p-type doped layer (1123p). The dotted line corresponds to the spectrum obtained from the top of the layer, whereas the solid line corresponds to the back incidence, through the glass substrate. 
deduced from Raman spectroscopy for the more hydrogen-diluted sample 1123P (93\%) whereas 0715P showed a lower crystalline fraction $(88 \%)$. Moreover, the sample $1123 \mathrm{P}$ also presented a room temperature dark conductivity $(2.6 \mathrm{~S} / \mathrm{cm})$ almost three times higher than the sample $0715 \mathrm{P}$ $(0.9 \mathrm{~S} / \mathrm{cm})$, which was the best p-type layer obtained at $90 \%$ hydrogen dilution. This result indicates that a higher atomic hydrogen concentration enhances the crystallinity of p-type films.

\subsection{Study of very thin layers}

Device structures such as thin film solar cells or field effect transistors require the deposition of doped layers often thinner than $0.1 \mu \mathrm{m}$. Since the material could be more defective at the initial stage of growth these layers could present poorer properties than the thicker films previously studied. In order to clarify this point, very thin $\mathrm{p}$ - and n-type layers were deposited (1123P and $1124 \mathrm{~N})$. These samples presented good electrical properties and the crystalline fraction was not reduced. The Raman spectra were obtained for front and back incidence (through the glass substrate). No differences were observed for the thin n-type layer, which presented in any case a high crystalline fraction (93\%). By contrast, the crystalline fraction of the p-type layer estimated from the back spectrum was lower than that deduced from the front as shown in Fig.6. This result suggests an amorphous or less crystalline phase at the initial stage of growth in the case of p-type layers. This effect could be related to the enrichment of boron at the substrate-layer interface observed by SIMS, which could alterate the nucleation of the film.

\subsection{Technological aspects: cross contamination}

Our HWCVD multichamber set up was designed to obtain devices such as thin film p-i-n solar cells. We reserved one chamber for the exclusive deposition of intrinsic material in order to avoid any unwanted incorporation of dopants in the active layer of the device. However, since both p- and n-layers are obtained in the same chamber, cross contamination should be reduced as much as possible to obtain good devices. Fig.7 shows several SIMS profiles of nominally undoped layers deposited in the chamber intended to obtain doped material. The solid line is the phosphorous concentration in an undoped layer obtained after a highly n-type sample. We observe that the phosphorous concentration fell down quickly (in about 5 minutes of process) to levels which are due to interference with $\mathrm{SiH}_{\mathrm{x}}$ groups rather than to actual phosphorous contamination, as was pointed out in 3.1. Therefore, cross contamination of phosphorous can be easily solved. Broken lines refer to the boron concentrations in three undoped layers each one obtained after a p-type deposition. The boron concentration in the sample obtained without any previous treatment remained constant along the whole profile at a similar level to the former p-type layer. When we changed the wire, the boron contamination was reduced in more than one order of magnitude, but this treatment would not be feasible since the chamber should be very often exposed to air. Finally, after fifteen minutes of deposition of intrinsic material on the reactor walls (burying), boron concentration was reduced to levels where its effect could only be the compensation of the material. Furthermore, by burying we avoided to open the chamber. 


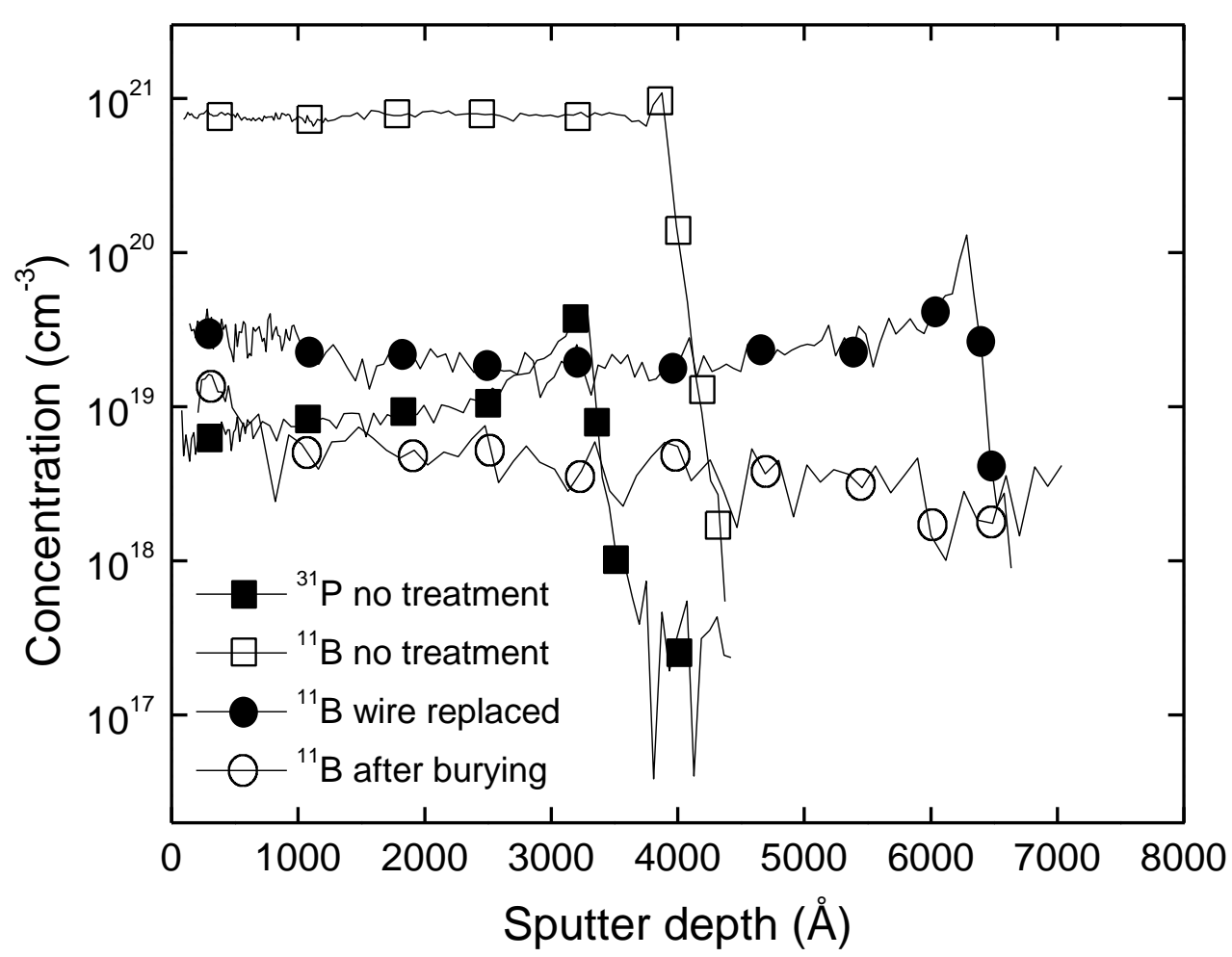

Figure 7. SIMS depth profiles of residual doping atoms. Symbol corresponds to mass 31 (phosphorus or SiHx complexes) in an undoped film deposited after an n-type deposition, whereas refer to mass $11\left({ }^{+} \mathrm{B}^{11}\right)$ in an undoped layer obtained after a p-type deposition without any treatment, after replacing the wire and

\section{Conclusions}

The HWCVD technique allows to obtain $\mu \mathrm{c}-\mathrm{Si}: \mathrm{H}$ at low substrate temperatures $\left(<300^{\circ} \mathrm{C}\right)$ and fast growth rates (>10 $\mathrm{A} / \mathrm{s}$ ), which makes it specially interesting for industrial applications. Our group is nowadays studying the HWCVD technique and its viability for the deposition of solar cells and thin film transistors. One of the key issues to obtain these devices is the possibility of in-situ dope the films and the achievement of both p- and n-doped layers with good electronic and structural properties. In this work we show that it is possible to obtain device quality doped $\mu \mathrm{c}-\mathrm{Si}: \mathrm{H}$ by the HWCVD technique.

P-doped samples suitable for device application were achieved for boron solid phase concentrations in the order of $10^{21} \mathrm{~cm}^{-3}$ (solid phase B/Si ratios well over 1\%). Amorphisation of these layers at such high dopant concentrations could be prevented by lowering the substrate temperature to $125^{\circ} \mathrm{C}$ and increasing the hydrogen dilution to $95 \%$. These deposition technological parameters not only enhanced the crystallinity but also improved the electrical properties of p-type samples. In the case of n-type doping, phosphorus solid phase concentrations about $10^{20} \mathrm{~cm}^{-3}$ (solid phase P/Si ratios lower than $0.1 \%$ ) were enough and both good electrical and structural properties were obtained.

The optimised layers could be scaled to thicknesses proper for devices maintaining good structural and electrical properties. Only in the case of the very thin p-layer a less crystalline initial growth was observed, as deduced from the back Raman spectrum (through the glass substrate). This effect 
could be due to the boron enrichment at the initial stages of growth observed by SIMS, which could alterate the nucleation of the film degrading its crystallinity.

Some technological conclusions could be deduced from the nominally undoped samples obtained in the same chamber after $\mathrm{p}$ - and n-type heavily doped layers. These results seem to indicate that multichamber HWCVD reactors are necessary to obtain devices and different chambers should be used for intrinsic and doped layers. The same chamber could be used to obtain both p- and n-type layers if the reactor walls are buried after any process, especially after depositing a p-layer.

\section{Acknowledgments}

This work has been carried out under contract JOR3-CT97-0126 of the JOULE programme of the EC, and with the aid of the CICYT of the Spanish Government. The authors wish to thank the Scientific-Technical Services of the UB by XRD and Raman Spectroscopy and the SIMS Service of the UB.

\section{References}

[1] M.A. Green, Prog. Photovolt. Res. Appl., 2, 87-94 (1994)

[2] Z. Shi and S.R. Wenham, Prog. Photovolt. Res. Appl., 2, 153-162 (1994)

[3] M. Pauli, M. Doscher, G. Salentiny, F. Homberg and J. Muller, $11^{\text {th }}$ EC Photovoltaic Solar Energy Conference, 525-528, Montreux (1992)

[4] T. Baba, M. Shima, T. Matsuyama, S. Tsuge, K. Wakisaka and S. Tsuda, $13^{\text {th }}$ European Photovoltaic Solar Energy Conference and Exhibition, Volume II, 1708-1711, Nice (1995)

[5] R.E.I. Schropp, K.F. Feenstra, E.C. Molenbroek, H. Meiling, J.K. Rath, Philos. Mag. B71 321 (1997)

[6] H.N. Wanka, R. Zedlitz, M. Heintze, M.B. Schubert, $13^{\text {th }}$ European Photovoltaic Solar Energy Conference and Exhibition, Volume II, 1753-1756, Nice (1995)

[7] J.K. Rath, R.E.I. Schropp, Mat. Res. Soc. Symp. Proc. Vol. 557, in press, San Francisco (1999)

[8] H. Meiling, A.M. Brockhoff, J.K. Rath and R.E.I. Schropp, Mat. Res. Soc. Symp. Proc. Vol. 507, 879-890, San Francisco (1998)

[9] H. Tarui, T. Matsuyama, S. Okamoto, H. Dohjoh, Y. Hishikawa, N. Nakamura, S. Tsuda, S. Nakano, M. Ohnishi and Y. Kuwano, Jpn. J. Appl. Phys., 282436 (1989)

[10] Z. Iqbal, S. Veprek, A.P. Webb and P. Capezzuto, Solid State Commun. 37, 993 (1981)

[11] R.S. Flückiger, Ph. D. Thesis, University of Neuchâtel (1995)

[12] C. Voz, D. Peiró, M. Fonrodona, D. Soler, J. Bertomeu and J. Andreu, $2^{\text {a }}$ Conferencia de dispositivos electrónicos, CDE-99, Madrid (1999) 